Teresa Laguna Paúl, (Coordinadora), Facistol de la Catedral de Sevilla. Estudios y recuperación, Sevilla, Editorial Universidad de Sevilla/Cabildo de la S.M.P.I. Catedral de Sevilla, 2016, 259 pp.

\title{
UN MUEBLE EXCEPCIONAL RECUPERADO EN LA CATEDRAL HISPALENSE
}

Ma Mercedes Fernández Martín* Universidad de Sevilla

La obra, coordinada por la profesora Teresa Laguna Paúl, es fruto del proyecto Un modelo digital de información para el conocimiento y gestión de Bienes Inmuebles del Patrimonio Cultural (HAR2012-34571), llevado a cabo por un equipo interdisciplinar de técnicos en conservación e investigadores. Los estudios que en ella se recogen vienen a solventar muchas cuestiones, hasta ahora imprecisas o ignoradas por quienes habían abordado el estudio de este mueble litúrgico. En este trabajo se analizan de forma exhaustiva los datos ya conocidos, pero a la vez se aportan otros que complementan o permiten nuevas teorías, donde se hace una reflexión que confirma ideas o desestima otras anteriormente asumidas. Está articulada en seis amplios capítulos donde se analiza pormenorizadamente la función, los materiales y técnicas artísticas empleadas en la realización del facistol.

En el primer capítulo Laguna Paúl realiza un estudio histórico-artístico de la pieza, ejemplo paradigmático del mobiliario litúrgico renacentista español. Diseñado por Hernán Ruiz el Joven, en su ejecución participaron los artistas más importantes del momento como el maestro mayor de carpintería Alonso Ruiz, el ensamblador Magnus Homan, los escultores Juan Marín, Francisco Hernández y Juan Bautista Vázquez, el fundidor Bartolomé Morel y el impresor Alonso Hernández de Córdoba. La exhaustiva labor de investigación llevada a cabo por la autora en el Fondo Capitular de la Catedral de Sevilla, ha aportando un amplio apéndice documental donde se recoge todo el proceso desde el diseño, los materiales, fases de la obra, la participación de los diferentes artífices, hasta su colocación en el coro.

*E-mail: mmfm@us.es 
En el segundo de los textos José María Guerrero Vega analiza la forma y el funcionamiento del facistol, donde destaca el equilibrio logrado entre estructura, función y forma. Gracias al desmontaje llevado a cabo para su restauración, además de la descripción formal del mueble, ha podido estudiar el complejo mecanismo de los diferentes cuerpos, especialmente el giro del cuerpo intermedio del mueble, aportando perspectivas axonométrícas del mueble para una mejor comprensión de su mecanismo. El tercer capítulo del libro, redactado por el restaurador Juan Carlos Castro Jiménez, recoge los análisis previos, con las alteraciones y patologías que presentaba el mueble antes de su restauración, y las intervenciones llevadas a cabo en el mismo, con la eliminación de algunos añadidos innecesarios y la sustitución de otras piezas que se encontraban deterioradas, así como la recuperación de su policromía original.

Francisco Pinto Puerto es el autor del texto dedicado a la traza y arquitectura del facistol pues, aunque no se conserva el diseño realizado por Hernán Ruiz, ha quedado testimonio del mismo en los dibujos y acotaciones realizados en el mueble por sus artífices. Pinto Puerto analiza la relación del facistol con la obra de Hernán Ruiz el Joven a través de su Manuscrito, poniendo en conexión el facistol de la catedral de Sevilla con otras obras coetáneas, así como la relación de la arquitectura con la música. Los dos últimos capítulos, más técnicos, están dedicados a la planimetría. En la era digital se hacía imprescindible el levantamiento planimétrico del mueble por medio de técnicas fotogramétricas, llevadas a cabo por Roque Ángulo Fornos, con la realización de una maqueta digital y una base de datos vinculada. Concluye el libro con un amplio apéndice gráfico donde se recoge buena parte de las ilustraciones que acompañan al texto, realizadas por los propios autores.

En definitiva, una obra interdisciplinar que abre nuevas vías a la investigación histórico-artística con la madurez, rigor y lucidez en los juicios y aportaciones que caracterizan a sus autores. Sus conclusiones son el resultado de la observación paciente, minuciosa y detenida de la obra. Sean bienvenidas este tipo de obras colectivas, que de manera monográfica recuperan una pieza tan importante del mobiliario litúrgico, avocado en la mayoría de los templos a su olvido o desaparición.

Fecha de recepción: 15 de octubre de 2016

Fecha de revisión: 2 de enero de 2017

Fecha de aceptación: 9 de enero de 2017 